\title{
Technical Analysis of Exoskeleton Robot
}

\author{
Sungjun Yeem¹, Jinyeong Heo1, Hongchul Kim², Yongjin Kwon ${ }^{1 *}$ \\ ${ }^{1}$ Department of Industrial Engineering, Ajou University, Suwon, South Korea \\ ${ }^{2}$ The 5th R\&D Institute, Agency for Defense Development, Daejeon, South Korea \\ Email: *yk73@ajou.ac.kr
}

How to cite this paper: Yeem, S., Heo, J., Kim, H. and Kwon, Y. (2019) Technical Analysis of Exoskeleton Robot. World Journal of Engineering and Technology, 7, 68-79.

https://doi.org/10.4236/wjet.2019.71004

Received: December 3, 2018

Accepted: January 4, 2019

Published: January 7, 2019

Copyright $\odot 2019$ by author(s) and Scientific Research Publishing Inc. This work is licensed under the Creative Commons Attribution International License (CC BY 4.0).

http://creativecommons.org/licenses/by/4.0/

(c) (i) Open Access

\begin{abstract}
Recently, the need for exoskeleton robots has been increased due to the advancement of robotic technologies and changes in the concept of how the robots can be utilized in direct contact with human bodies. The robots, once only used on the factory floor, are now becoming a part of human bodies, which provides the unprecedented level of muscle power boost and the increase of running speed. If used very carefully, the exoskeleton robots can be also used for patients' rehabilitation. The exoskeleton robots have many potential application areas; hence most advanced countries are currently developing various types of exoskeleton robots. Those robots can be classified into two major categories, namely the rigid type and the soft type. Each type has own advantages and disadvantages, while the carrying load capacity and the actuation speed can be quite different. There are also many technical difficulties in order to use the exoskeleton robots in the field. The aim of this study is, therefore, to introduce the trends of exoskeleton robot development in advanced countries, while providing the analysis on the technical merits and downside of robot types. The comparison chart also indicates the major technical directions, in which the future technology will be headed for, such as the improved robot response characteristics by employing advanced sensors and artificial intelligence. The robots are becoming smarter, lighter, and more powerful. It is foreseeable that the wearable robots can be a part of human life in the very near future.
\end{abstract}

\section{Keywords}

Exoskeleton Robot, Wearable Robot, Rigid Type Robot, Soft Type Robot, Artificial Muscle

\section{Introduction}

In recent years, the interests in the area of wearable robots have been rapidly increasing. In the past, the robots have been deployed in factory floors and isolated 
from the humans, due to the fact that the robots can seriously hurt or harm human beings in the event of direct contact. However, rapid technological development is making possible that the robots can become a part of human bodies and actually assist the human through direct contact [1]. This has never been possible. Wearable robot means a robot that imitates the joints of the human body and acts like a part of humans, mainly used to aid or assist humans by understanding the user's intention in order to perform certain actions. Various researches have been conducted that it can enhance human muscle power through wearing of such robots. Now, because the potential application areas of wearable robots are only limited by the imagination, many countries are actively studying the technologies, including South Korea [2].

Wearable robots were once only existed in the research laboratories and the shapes were mere replication of human hands or arms, for those who accidently lost their limbs. It was the prosthetic apparatus, and the technology was not mature enough to wear those artificial limbs. It was too bulky and cumbersome, and even dangerous to the human wearers. However, with the rapid advancement in technology, it is becoming smarter, lighter, safer, and more intelligent, so that advanced countries are now introducing many different types of wearable robots. Once only used for health care and prosthetic areas, the robots are becoming very powerful and can be used to carry a heavy load. The bulky and cumbersome mechanical exoskeleton is advancing into a highly mobile, lightweight, and smart suit with many functionalities. The application areas now include the healthcare, medical, construction, warehouse, material handling, manufacturing, sports, and military. Since the robot can reduce the physical workload of humans, while improving mobility and moving speed, the economic and ergonomic potential of this type of robot is considered enormous. The market is also growing rapidly worldwide, reaching an unprecedented level in a near future. Figure 1 shows the technological development of wearable robots from the 1960s till current time [3] [4] [5] [6].

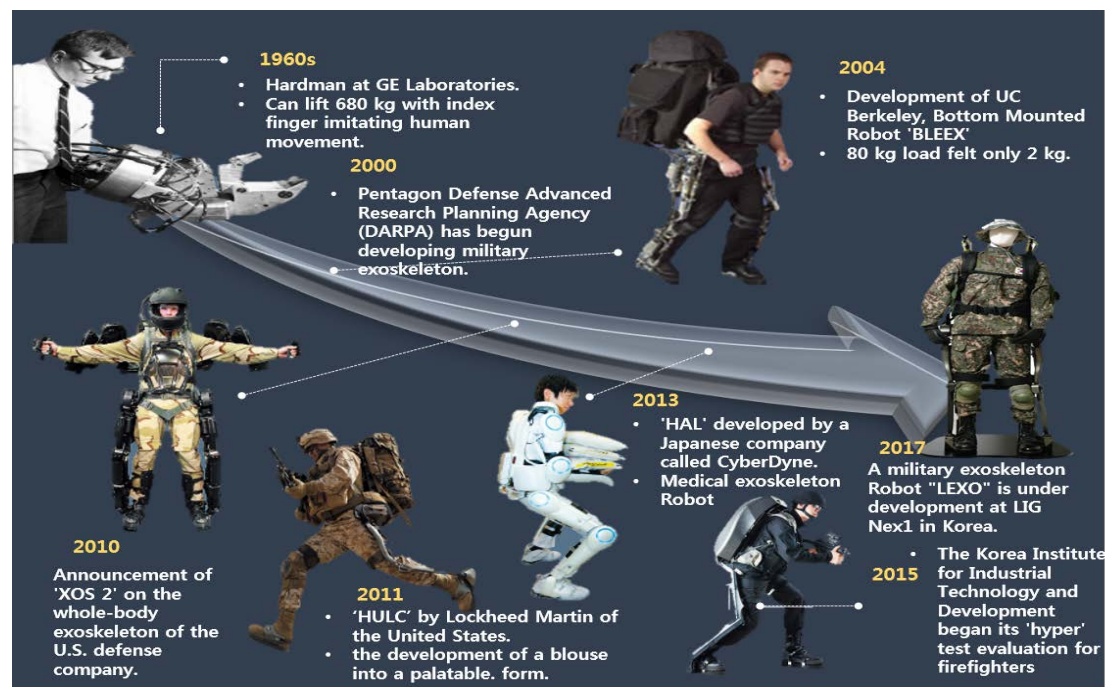

Figure 1. Changes in wearable robot technologies. 
In general, wearable robots can be divided into two major categories: 1) rigid exoskeleton wearable robots and 2) soft exo-suit wearable robots, according to the materials, structure and operation of the system. The advantage of a rigid exoskeleton wearable robot is that it transmits the single-acting frame to the same joint as the rotation of the actuator. In addition, it can be placed on the outside of the human body to support the weight (the payload of the robot). However, it is big and heavy compared to the human body; hence the robot can be bulky and cumbersome to operate. The large inertia also raises the power demand of the robot, which makes the power consumption a big issue and cause a very frequent battery replacement. On the other hand, in the case of a soft exo-suit wearable robot, since the material constituting the system is composed of cloth, soft plastics, and wire, it light-weight and much more comfortable to wear. However, there is a disadvantage that the power that the driver system can generate is substantially low; hence the power transmission efficiency is low. This means that the wearer cannot get a sufficient level of power boost from the robot. Despite these limitations and disadvantages, they are expected to be used in various fields. In any case, the interests in the application of robotic technology directly into the human bodies will continue to escalate, due to the fact that it will enhance the human performance in a level that we have never imagined. In this regard, this paper introduces the trends of current technological development and analyzes the future research direction of the wearable robot [7] [8] [9]. Figure 2 shows the major application areas of the exoskeleton.

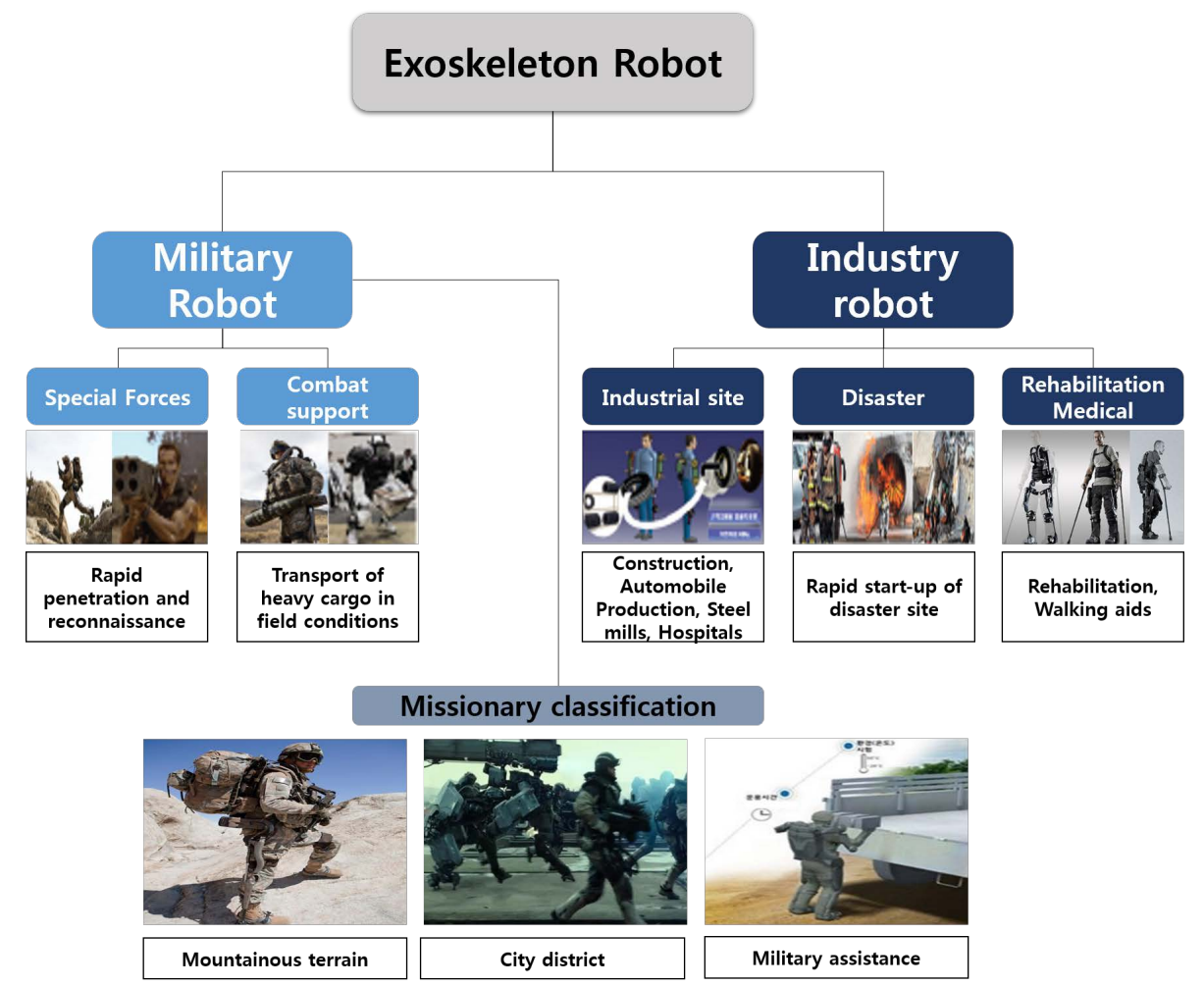

Figure 2. Categories of exoskeleton robots. 


\section{Current Trends of Exoskeleton Robot Development}

Exoskeleton robots are being actively developed in major countries, especially US and Japan. In the military and industrial sectors, the United States has achieved remarkable results in the fields of welfare and rehabilitation robots. Table 1 illustrates the development and operation of exoskeleton robots, mainly in the United States.

In the United States, military exoskeleton robots, such as BLEEX, HULC and XOS2 through the DARPA (Defense Advanced Research Projects Agency) funds, have been under development for more than 10 years. The metal exoskeleton is being replaced into a flexible material in order to realize the natural human movement. Currently, the latest version is not disclosed under military confidentiality, but HULC has the best technology. In particular, HULC has the

Table 1. USA-Summary of exoskeleton robot development [10]-[15].

\begin{tabular}{|c|c|c|c|c|c|c|}
\hline Nation & Figure & Model & $\begin{array}{c}\text { Wearing } \\
\text { parts }\end{array}$ & $\begin{array}{l}\text { Weight }(\mathrm{kg}) \text {, } \\
\text { Payload }(\mathrm{kg})\end{array}$ & $\begin{array}{l}\text { Velocity } \\
(\mathrm{km} / \mathrm{h})\end{array}$ & Purpose \\
\hline USA & & $\begin{array}{c}\text { HULC } \\
\text { (Human } \\
\text { Universal Load } \\
\text { Carrier) }\end{array}$ & Whole & $\begin{array}{l}24 \\
90\end{array}$ & 16 & Military \\
\hline USA & & XOS2 & Lower & $\begin{array}{l}68 \\
90\end{array}$ & - & Military \\
\hline USA & & $\begin{array}{c}\text { BLEEX2 } \\
\text { (Berkeley Lower } \\
\text { Extremity } \\
\text { Exoskeleton 2) }\end{array}$ & Lower & $\begin{array}{l}-, \\
90\end{array}$ & 7.2 & $\begin{array}{l}\text { Military } \\
\text { Industry }\end{array}$ \\
\hline USA & & Fortis & Whole & $\begin{array}{c}31 \\
16.3\end{array}$ & - & $\begin{array}{l}\text { Military } \\
\text { Industry }\end{array}$ \\
\hline USA & & e-LEGS & Lower & 20, & 3.2 & Rehabilitation \\
\hline USA & & $\mathrm{X} 1$ & Lower & $\begin{array}{c}26, \\
-\end{array}$ & - & $\begin{array}{c}\text { Industry } \\
\text { Rehabilitation }\end{array}$ \\
\hline USA & & EXSO & Lower & - & - & Rehabilitation \\
\hline
\end{tabular}


highest maneuver speed among other existing wearable robots using hydraulic drive systems. It is now known to be in the early stages of trial evaluation for commercialization. In Japan and other countries, muscle strengthening wearable robots are mainly developed for industrial and medical purposes. They use the EMG signal of the wearer to grasp the intention of the motion. Many of them are being used as rehabilitation and therapy robots. The major development case is illustrated in Table 2.

\section{Exoskeleton Wearable Robot}

\subsection{Rigid Exoskeleton Wearable Robot}

As mentioned in the previous chapter, wearable robots are typically used for military, industrial, rehabilitation, and training of other robots. This chapter introduces the roles and technology trends of rigid exoskeleton wearable robots

Table 2. Other countries-Summary of exoskeleton robot development [16]-[22].

\begin{tabular}{|c|c|c|c|c|c|c|}
\hline Nation & Figure & Model & $\begin{array}{c}\text { Wearing } \\
\text { parts }\end{array}$ & $\begin{array}{l}\text { Weight }(\mathrm{kg}), \\
\text { Payload }(\mathrm{kg})\end{array}$ & $\begin{array}{l}\text { Velocity } \\
(\mathrm{km} / \mathrm{h})\end{array}$ & Purpose \\
\hline Japan & & $\begin{array}{c}\text { WAD } \\
\text { (Walking } \\
\text { Assist Device) }\end{array}$ & Lower & $\begin{array}{c}2.6, \\
-\end{array}$ & - & $\begin{array}{c}\text { Industry } \\
\text { Rehabilitation }\end{array}$ \\
\hline Japan & & Powerloader & Whole & $\begin{array}{l}230 \\
100\end{array}$ & 8 & Industry \\
\hline Japan & & $\begin{array}{c}\text { HAL } \\
\text { (Hybrid } \\
\text { Assistive } \\
\text { Limb) }\end{array}$ & Whole & $\begin{array}{l}23 \\
70\end{array}$ & - & Rehabilitation \\
\hline Swiss & & ChairlessChair & Lower & $\begin{array}{c}2, \\
100\end{array}$ & - & Industry \\
\hline Israel & & ReWalk & Lower & $\begin{array}{l}20 \\
100\end{array}$ & 3 & Rehabilitation \\
\hline $\begin{array}{c}\text { NewZeal } \\
\text { and }\end{array}$ & & Rex & Lower & $\begin{array}{c}38, \\
-\end{array}$ & 0.18 & Rehabilitation \\
\hline France & & $\begin{array}{l}\text { HERCULE } \\
\text { (the French } \\
\text { Version of } \\
\text { Hercules) }\end{array}$ & Whole & $\begin{array}{l}25 \\
100\end{array}$ & 4 & Military \\
\hline
\end{tabular}


and chute-type muscle-strength-enhancing robots for each application field. The rigid exoskeleton type wearable robot has the main purpose of enhancing the muscle power by utilizing high output in a system made of solid material such as aluminum and composite plastic. However, it has a disadvantage that it is heavy and maneuverability is low. Using these features, the exoskeleton-type muscle strength-enhancing robot is mainly used for military and industrial purposes. For military use, it has been developed so as to carry heavy weight cannon shells or large-caliber machine guns. It is also being developed to carry heavy cargos or materials for industrial use. The following is a representative technology of the exoskeleton type muscle strengthening robot [10] [23], which is illustrated in Table 3 and Table 4.

- HEXAR-CR50

- Rigid exoskeleton robot system developed for military and industrial applications.

- HULC

- The Human Universal Load Carrier is the 3rd generation exoskeleton system.

- It takes up to 200 pounds without impeding the wearer.

- It decreases its wearer's metabolic cost.

- Hercule

- It benefits from an articulated knee.

- HERCULE will increase the carrying capacity of the soldier (100 kg in total and $40 \mathrm{~kg}$ on the arm).

- HAL

- HAL is the medical device for people who have disorders in the lower limb and people whose legs are weakening.

HULC and HECULE are used for military purposes and worn over the whole body. Those use the hydraulic actuators for high power output. In addition,

Table 3. HEXAR and HULC [10] [23].

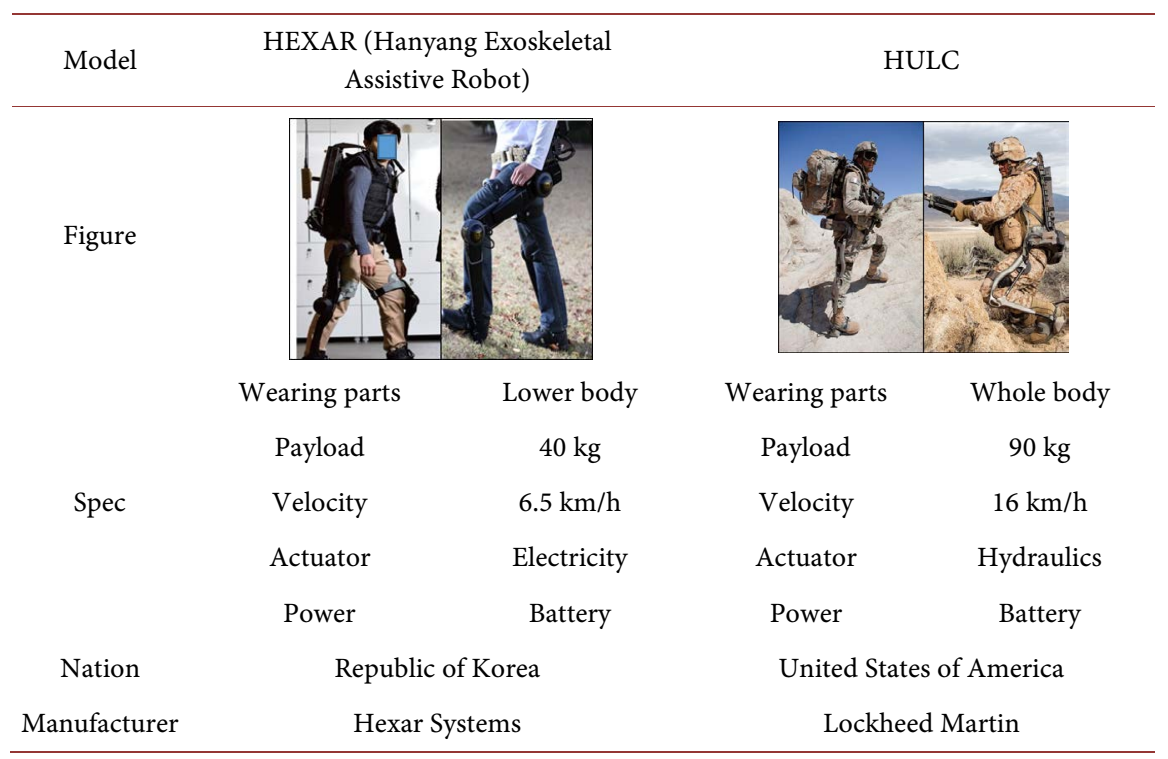


Table 4. HERCULE and HAL [18] [22].

\begin{tabular}{|c|c|c|c|c|}
\hline Model & $\mathrm{He}$ & & \multicolumn{2}{|c|}{ HAL } \\
\hline \multicolumn{5}{|l|}{ Figure } \\
\hline & Wearing parts & Whole body & Wearing parts & Whole body \\
\hline & Payload & $90 \mathrm{~kg}$ & Payload & $23 \mathrm{~kg}$ \\
\hline \multirow[t]{3}{*}{ Spec } & Velocity & $16 \mathrm{~km} / \mathrm{h}$ & Velocity & - \\
\hline & Actuator & Hydraulics & Actuator & Electricity \\
\hline & Power & Battery & Power & Battery \\
\hline Nation & \multicolumn{2}{|c|}{ France } & \multicolumn{2}{|c|}{ Japan } \\
\hline Manufacturer & \multicolumn{2}{|c|}{ RB3D } & \multicolumn{2}{|c|}{ Cyberdyne } \\
\hline
\end{tabular}

HEXAR, which is worn only on the undergarment, and HAL, which is used for rehabilitation, use an electric actuator. Commonly made of aluminum, plastic, etc., it is heavy and bulky, making it difficult to attach and detach. It is often used as a form that increases the maximum load that the wearer can overcome when carrying heavy objects. In addition, although a different method is used, a muscle strengthening system for overcoming the wearer's weight is also made into an exoskeletal muscle strength enhancing robot.

\subsection{Soft Exo-Suit Wearable Robot}

Unlike a rigid exoskeleton wearable robot, a soft exo-suit wearable robot is a robot composed of a soft material. Research is underway on a system that does not interfere with the human body movement due to its light weight and high maneuverability. The most important research direction is the development of a lightweight power source that can replace heavy electric motors or hydraulic motors. One must yet develop a lightweight power source with high power output and precision. The following is a representative technology of the soft exo-suit wearable robots [24] [25], which is illustrated in Table 5 and Table 6.

- Exo-Glove Poly

- Users are only required to wear a thin glove consisting of silicone with a few tendons passages weighing less than $200 \mathrm{~g}$.

- Separation of the glove and actuation system means the glove is compact and lightweight.

- Users can wear the Exo-Glove Poly without burdening their hands or feeling ashamed by wearing a bulky robotic device.

- Soft Exo-Suit

- These robots augment the capabilities of healthy individuals in addition to assisting those with muscle weakness or patients who suffer from physical or neurological disorders. 
Table 5. Exo-GlovePoly and Soft Exo-suit [24] [25].

\begin{tabular}{|c|c|c|c|c|}
\hline Model & \multicolumn{2}{|c|}{ Exo-Glove Poly } & Soft & \\
\hline \multicolumn{5}{|l|}{ Figure } \\
\hline & Wearing parts & Hands & Wearing parts & Lower body \\
\hline & Payload & $194 \mathrm{~g}$ & Payload & - \\
\hline \multirow[t]{3}{*}{ Spec } & Velocity & - & Velocity & $4.5 \mathrm{~km} / \mathrm{h}$ \\
\hline & Actuator & Electricity & Actuator & Electricity \\
\hline & Power & Battery & Power & Battery \\
\hline Nation & \multicolumn{2}{|c|}{ Republic of Korea } & \multicolumn{2}{|c|}{ United States of America } \\
\hline Manufacturer & \multicolumn{2}{|c|}{ Seoul National University } & \multicolumn{2}{|c|}{ Harvard University } \\
\hline
\end{tabular}

Table 6. Robo-glove and Sixpad [26] [27].

\begin{tabular}{|c|c|c|c|c|}
\hline Model & \multicolumn{2}{|c|}{ Robo-Glove } & \multicolumn{2}{|c|}{ Sixpad } \\
\hline \multicolumn{5}{|l|}{ Figure } \\
\hline & Wearing parts & Hands & Wearing parts & Whole body \\
\hline & Payload & - & Payload & $49 \mathrm{~g}$ \\
\hline \multirow[t]{3}{*}{ Spec } & Velocity & - & Velocity & \\
\hline & Actuator & Pneumatic & Actuator & Electricity \\
\hline & Power & Battery & Power & Battery \\
\hline Nation & \multicolumn{2}{|c|}{ United States of America } & \multicolumn{2}{|c|}{ Japan } \\
\hline Manufacturer & \multicolumn{2}{|c|}{ General Motors } & \multicolumn{2}{|c|}{ MTG } \\
\hline
\end{tabular}

- The wearer's joints are unconstrained by external rigid structures, and the worn part of the suit is extremely light.

- Robo-Glove

- Robo-glove has potential applications in prosthetic devices, rehabilitation aids and people with impaired or limited arm and hand muscle strength.

- Sixpad

- The body training gear "SIXPAD" is a body training product that trains muscles through EMS.

In the rehabilitation and training field, it is important to reduce the weight of the suit-type muscle strengthening robots. Unlike the rigid exoskeleton wearable robot, the weight of the system itself cannot be dispersed, so the wearer has to bear the weight on his body. Therefore, the development of a power source with high efficiency with low weight is given a priority. On the other hand, in order to 
minimize the weight, other types of robots are available. It is a robot that stimulates the human muscles with electric pulses, rather than a robot that assists the body through the power source, thus enhancing the mobility of the human body. However, these types of robots cannot overcome the muscle weakness of fatigue problems. The soft exo-suit wearable robots used in the military field are being developed to improve muscle endurance rather than muscle strength. However, as can be seen in Table 6, slow speed and low payloads have to be overcome due to insufficient power sources as well as their low weight.

\section{Deficiencies and Future of the Exoskeleton Robot}

The wearable robots are providing an unprecedented level of robotic applications, which can be directly adhering on the human bodies. This type of technology can fundamentally alter the ways that the human live. The economy can benefit enormously and a new level of job standards may need to be devised as the robot power becomes a part of human workers. However, in order to be used as efficiently as projected, there are many problems to be solved. First of all, the current technology cannot provide the adequate response speed and comfort to the wearer. This means that each time the wearer tries to move, the robot becomes a drag, hence takes a considerable amount of effort to actuate the robot. Due to this reason, the fatigue level of the robot wearer becomes almost the same level of the non-wearer, when the same tasks are performed. This problem must be overcome, if the wearable robots need to be utilized in projected application areas. The sensing and prediction of wearer's intended motion should be precisely communicated to the robot without any noticeable delay in the robot response. In other words, the wearer should feel the robot as natural as a part of his own body.

Second of all, even though, the rigid exoskeleton wearable robots can sufficiently perform the role of supporting and dispersing the heavy load, there is a battery problem. The current technology can only provide at a maximum of 30 minutes of actuation time. If the battery should last longer, the size and capacity becomes out of proportion, causing the battery too heavy for the wearer. Other source of power generation, such as engines or fuel cells, contains other problems that also need to be resolved. The weight and capacity of the power source should be considerable improved. The electric motor and the transmission on the robot joint should also be improved. Those should become considerably smaller and quieter. The current motors and transmissions are directly borrowed from the industrial robots, and they are not adequate for directly human use. As for the soft exo-suit wearable robots, they should also overcome the same type of problems, such as batteries, power source, and fatigue. In addition, this type should also improve the problems stemming from the slow motion speed and low payload. This even further complicates the problems, if the soft exo-suit robots need to be utilized in the field.

Despite the efforts made so far, the current level of technology is still not 
Table 7. Features of rigid exoskeleton and soft exo-suit wearable robots.

\begin{tabular}{lcc}
\hline \multicolumn{1}{c}{ Feature } & $\begin{array}{c}\text { Rigid Exoskeleton } \\
\text { Wearable Robot }\end{array}$ & $\begin{array}{c}\text { Soft Exo-Suit } \\
\text { Wearable Robot }\end{array}$ \\
\hline - Material & Aluminum, plastic, etc. & Fabrics, artificial muscles, wires, etc. \\
- Weight and Volume & Heavy and bulky & Light and small \\
- Maximum Output & 1 to 10 times the strength & 0 to 0.1 times the strength \\
- Joint Structure & Simple & Complicacy \\
- Attachment/Detachment & Difficult & Easy \\
- Main Purpose & $\begin{array}{c}\text { Muscle Strength } \\
\text { Enhancement }\end{array}$ & Muscle Power Assist \\
\hline
\end{tabular}

satisfying the users. Also, any injury should not occur to the users, hence the accident prevention technology should be developed. Therefore, securing the technological capability to solve these problems is the key issue. It is considered to be a field that can make a great progress in the future. Table 7 summarizes the results of the analysis [10]-[17].

\section{Conclusion}

In this paper, we investigated the material, structure, operational method, and research trends of the wearable robots in developed countries. The human's desire to increase muscle strength as well as to improve mobility can be realized, using this technology. While the first exoskeleton robot could merely boost the muscle strength of the wearer, the future robots are going to provide many improved functionalities to the wearer. Those may include the heating and cooling functions to the wearer, the prevention of the robot fall, the lighting and proximity sensing capabilities, and the autonomous path finding and the automated walking functions. It may evolve into an autonomous walking robot and the human can relax in a robot, while the robot can automatically navigate itself through obstacles. It can be confirmed that the demand for wearable robots will continue to increase along with the advancement of technologies. At this current stage, the rigid exoskeleton robots are still too large and bulky; hence it can be quite dangerous to the wearer in the event of robot fall. With the rapid advancement of technologies, the wearable robots can be a natural extension of the human bodies, easily detaching and attaching on the limbs as the need desires. This will create a complete new robotic market that is geared towards the improvement of human performance, while reducing the muscle fatigue.

\section{Acknowledgements}

This work was supported by the Agency for Defense Development (ADD) under the Contract No. UD170017ID.

\section{Conflicts of Interest}

The authors declare no conflicts of interest regarding the publication of this paper. 


\section{References}

[1] Kim, H., Shin, Y. and Kim, B. (2017) Kinematic Robust Motion Classification Based on Kinematic Strength Robot. Korea Institute of Military Science and Technology, Robotics and Systems, 1692-1693.

[2] Jang, J. and Song, W. (2016) Technology Changes in Wearable Robots. Journal of the KSME, 56, 42-46.

[3] Lee, D., Jung, J., Kim, B., Son, Y. and Shin, H. (2017) Trends in Wearable Assistive Robotics Technology. Electronic Communication Trend Analysis, 32, 21-30.

[4] Asbeck, A.T., De Rossi, S.M.M., Galiana, I., Ding, Y. and Walsh, C.J. (2014) Stronger, Smarter, Softer: Next-Generation Wearable Robots. IEEE Robotics \& Automation Magazine, 21, 22-33. https://doi.org/10.1109/MRA.2014.2360283

[5] Hu, X. and Yu, H.L. (2014) Study on an Exoskeleton Training Device for Hand Function Rehabilitation. Journal of the Korean Rehabilitation Society, 2014, 93-96.

[6] Ha, E. and Hwang, W. (2016) A Study on the Design and Control Lower Extremity Exoskeleton Robot. Control Robot System Society Conference, 2016, 384-385

[7] Lee, H. and Han, C. (2014) Technical Trend of the Lower Limb Exoskeleton System for the Performance Enhancement. Journal of Institute of Control, Robotics and System, 20, 364-371. https://doi.org/10.5302/J.ICROS.2014.14.9023

[8] Lim, J., Chang, K. and Kim, H. (2012) Trend in Exoskeleton Robots. Defense Technology Conference, 7, 478-483.

[9] Chu, K., Oh, S., Choi, J. and Kim, K. (2010) Development of Exoskeleton Robot Used to Assist the Lower Limbs Power for Soldier's Combat Enhancement. Information and Control Conference, Vol. 10, Ulsan, 22-23 October 2010, 354-355.

[10] HULC (2018). https://bleex.me.berkeley.edu/research/exoskeleton/hulc/

[11] XOS2 Exoskeleton (2018). https://www.army-technology.com/projects/raytheon-xos-2-exoskeleton-us/

[12] Berkeley Robotics \& Human Engineering nLaboratory-BLEEX (2018). https://bleex.me.berkeley.edu/research/exoskeleton/bleex/

[13] Smerobotics-Fortiss (2018). https://www.fortiss.org/en/research/projects/smerobotics/

[14] IhmcRobotics-X (2018). http://robots.ihmc.us/x1-mina-exoskeleton/

[15] Exsobionics (2018). https://eksobionics.com/

[16] Honda-WAD (2018). https://world.honda.com/Walking-Assist/

[17] Panasonic, ActiveLink-Powerloader (2018). https://exoskeletonreport.com/2015/10/panasonic-activelink-company-profile/

[18] Cyberdyne HAL (2018). https://www.cyberdyne.jp/english/products/LowerLimb_medical.html

[19] Noonee-Chairlesschair (2018). https://www.noonee.com/

[20] Rewalk (2018). https://rewalk.com/

[21] Rex Bionics-REX (2018). https://www.rexbionics.com/

[22] Rb3d HERCULE (2018). https://www.rb3d.com/en/exoskeletons/

[23] HEXAR-Cr50 Objective and Overview (2018). http://www.hexarsystems.com/new/product/product_p04.php?p_idx=3

[24] Seoul National University Biorobotics Laboratory Exo-Glove Poly (2018). http://biorobotics.snu.ac.kr/rehabilitation-robot/exo-glove-poly 
[25] Harvard Biodesign Lab Soft Exosuits (2018).

https://biodesign.seas.harvard.edu/soft-exosuits

[26] NASA Technology Transfer Robo-glove (2018).

https://technology.nasa.gov/patent/MSC-TOPS-37

[27] MTG Sixpad (2018). https://www.sixpad.jp/sp/en/emsrevolution/index.html 